\title{
Characterizing the Intensity and Dynamics Change Relationship Between the Land-Use and Landscape Pattern in the Ordos Bojiang Basin
}

\author{
Harrison Odion Ikhumhen*(**)†, Tianxin $\mathrm{Li} *(* *)$ and Nametso Matomela*(**) \\ *School of Energy and Environmental Engineering, University of Science and Technology Beijing, 30 Xueyuan Road, \\ Haidian District, 100083, Beijing, China \\ **Beijing Key Laboratory of Resource-oriented Treatment of Industrial Pollutants, Beijing, 100083, PR China \\ †Corresponding author: Harrison Odion Ikhumhen; harryspk@yahoo.com
}

\section{Nat. Env. \& Poll. Tech.} Website: www.neptjournal.com

Received: 09-07-2019 Accepted: 19-09-2019

\section{Key Words:}

Land Use; Landscape pattern; Transition intensity; Bojiang Lake; Pontius model; Anthropogenic activities

\begin{abstract}
This paper seeks to analyse the present and future land-use change transition intensity (using Pontius intensity model) and landscape pattern using landscape metrics to investigate the relationship between the land cover regions, landscape pattern and the changes in the size of Bojiang lake in Ordos basin from 1987-2017. The accelerated changes in each land use region from 1987 and 2017 subsequently led to changes in landscape pattern. The changes experienced within 1987 and 2017 including the future changes indicated that the grassland and sparsely vegetated region increased significantly, dominating the study region which however indicated an increase in anthropogenic activities like agricultural activities in the study region. Based on our observation in this study, the change in each land use region although showed a significant relationship with the change in water region including Bojiang lake, other external factors also contributed to the changes in the size of the lake.
\end{abstract}

\section{INTRODUCTION}

Wetland is referred to a very significant ecological environment and also one of the most important living environments known to man. It is responsible for controlling our ecological environment including plant and animal species with a global area coverage of only $6.2-7.6 \%$ of the entire world's land surface (Finlayson 2012, Lehner \& Döll 2004). Wetland plays a major role in ensuring the provision of certain ecological services such as ground and freshwater supply, biodiversity, flood and drought mitigation, erosion control and mitigation of water pollution (Bolund \& Hunhammar1999, Zedler \& Kercher 2005, Ramsar 2007, Alabisky et al. 2011). Within the timeframe of 10 years between 1990 and 2000, about 30\% of China's natural wetland has been lost and in the past 50 years, over $50 \%$ of wetlands in China have been lost (Guo et al. 1990, Ren et al. 2007, Cyranoski 2009). The driving forces for this decrement experienced in the wetlands are believed to be the changes in climate and increased water extractions from anthropogenic activities. For instance, the continuous drought experienced in the popularly known Yangtze river system and the southwest China's wetland area is believed to possibly result in the decline in the wetland areas in those regions (Cao et al. 2012, Tian et al. 2016). The development of remote sensing technology has been advantageous in ensuring proper evaluation of the ecological health of the environment (Cao 2013). For instance, to monitor wetland changes, the multi-spectral and multi-temporal images (Landsat images) have proven to be quite advantageous because of the possibility to quickly differentiate the Spatio-temporal quality of a landcover region with high accuracy especially in cases of worse climatic conditions such as droughts (Cao et al. 2012) and floods (Hereher 2010, Tian et al. 2016). Land-use change and global processes like climate change, increased population, urbanization, land degradation etc. are interrelated (Kertész et al. 2019). With the continuous growth in population globally (different rates at the different locations in the world) the demand for space, food and infrastructure also increases which requires changes in the land use structure (Szabó et al. 2016). The intensification of the urban growth experienced globally is accompanied by a large increment in the consumption of natural resources, increased habitat fragmentation and ecological disturbance (biodiversity loss) (Foley et al. 2005, Lawler et al. 2014). The establishment of an efficient and effective strategy to manage and conserve the present and future land use is based on adequate knowledge of the land use process (Al-doski et al. 2013, Alo \& Pontius 2008). 
Shallow assessment of land-use change might not reveal the most significant land-use change dominancy signals which might lead to insufficient management approaches and conservative measures (Pontius et al. 2004). Several studies made use of the land-use transition matrices to compare changes between two different time intervals. The studies however rarely assessed the process behind the change in landscape pattern. The identification of these processes allows us to link the observed land-use transitions to the possible causes (Pontius et al. 2004, Teixeria et al. 2014, Braimoh 2006). Several studies have investigated the relationship between landscape pattern changes and its effect on the ecological process (Dadashpoor 2018, Echeverría et al. 2012, Nagendra et al. 2004, Schröder \& Seppelt 2006, Lausch et al. 2015, Tyre et al. 2006), some other have studied just the changes in landscape patterns (Abdullah \& Nakagoshi 2006, Cabral \& Costa 2017, Frondoni et al. 2011, Hladnik 2005, Kienast et al. 2015, Wan et al. 2015), some scholars also studied the relationship between changes in landscape pattern and driving forces and urbanization growth (Bürgi et al. 2004, Dadashpoor 2018, Aguilera et al. 2011, Chen et al. 2014, Luck \& Wu 2002, Reis et al. 2015). However, there are very few studies to analyse the magnitude and intensity of the present and future land-use change and its relationship with the landscape pattern changes and ecological process. In our study, we will be focusing on finding out which land use region are intensively targeted or avoided and analyse the relationship with the degraded wetland from 1987-2017 and also in the next 100 years. We mainly targeted the vegetative regions and the water region to reveal the details of the water reduction and expansion of the vegetative region including the underlying process, dynamic trends and possible driving forces. To the best of our knowledge, this study will be the first to apply the transition intensity approach in the popularly known Ordos Reserve basin whose lake has been going through a series of area reduction.

The following research questions were investigated in this study.

- What are the main LULC types and the transition intensity of the area coverage in the Ordos Catchment from 1987-2017 and the predicted future (2017-2117)?

- What are the changes in landscape pattern and its relationship with the LULC regions?

- What is the influence of the changes in land use and landscape pattern on the changes in the water size?

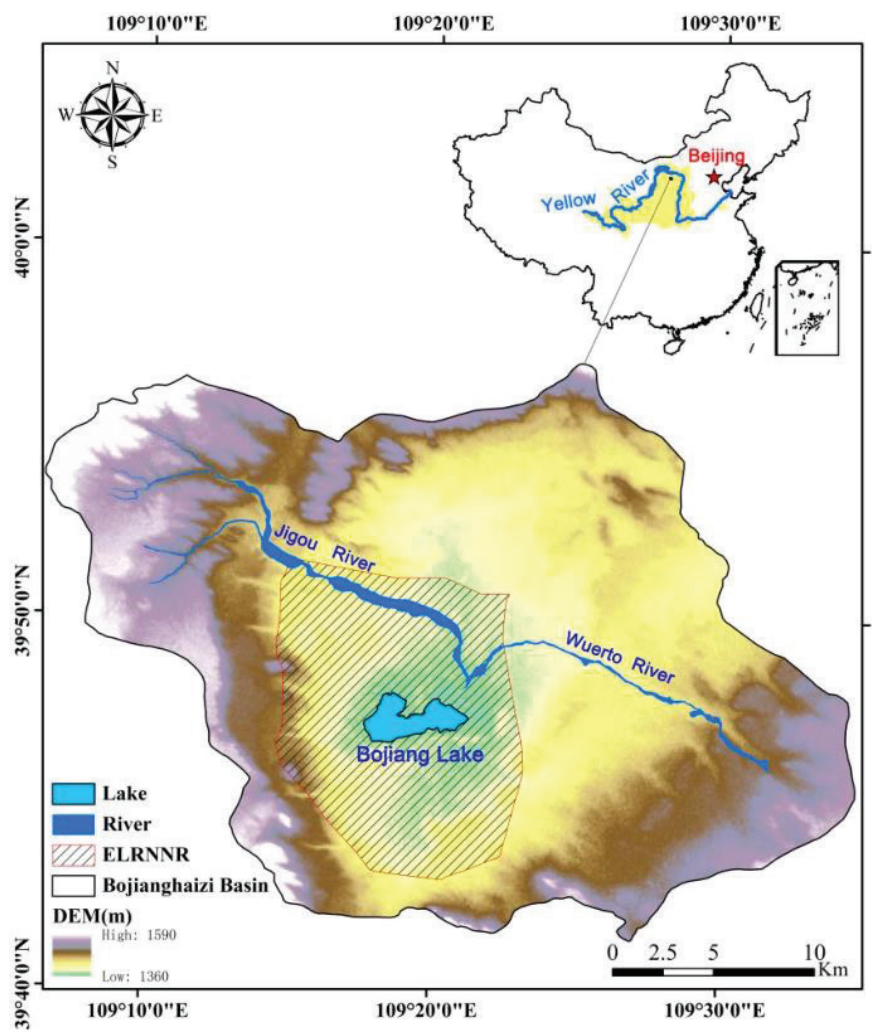

Fig. 1: Regional location of Ordos National Nature Reserve (Kang 2017). 


\section{DATA AND METHODOLOGY}

\section{Study Area}

Ordos National Nature Reserve located in Ordos city of Inner Mongolia Autonomous Region in China is about $45 \mathrm{~km}$ west of Dongsheng District with an area coverage of $155.66 \mathrm{~km}^{2}$ (situated in latitude $39^{\circ} 41^{\prime} 40^{\prime \prime}$ ' to $39^{\circ} 56^{\prime} 2^{\prime \prime}$ and longitude $109^{\circ} 6$ ' $30^{\prime \prime}$ to $109^{\circ} 32^{\prime} 50^{\prime \prime}$ ). The reserve is located in the central-southern section of the Bojiang lake basin with a drainage area coverage of about $640 \mathrm{~km}^{2}$. The annual mean temperature from 1971-2000 of the reserve is approximately $6.16^{\circ} \mathrm{C}$. The annual mean precipitation, on the other hand, is approximately $381.2 \mathrm{~mm}$ in this region, more than half of the precipitation falls between the period of July and August. Bojiang lake is situated in the central basin with Jigou River and Wuertu River flowing through it (Fig. 1). The major vegetation types in this reserve are grasslands and shrubs. According to Liang et al. (2011), Bojiang lake's source of water is the water derived from precipitation and lateral runoff in the closed basin accounting for $22 \%$ of the total water recharge from 1996 to 2005. Because of the significance of this wetland to Ordos reserve, more attention should be paid towards its protection which is why it is the only wetland in the semi-arid and arid region of China to be included in the Ramsar list of globally important wetlands. Larus Relictus (Relict Gull) is a species that according to the Convention of International Trade in Endangered Species of Wild Fauna and Flora (CITES) and the Convention on the Conservation of Migratory Species (CMS) is recently in urgent need of protection this makes this nature reserve a very important reserve solely targeted towards the protection of this specie (Liu et al. 2008).

\section{Data}

In this research, the remote sensing images for 1987, 1995, 2003, 2010, 2017 were obtained via the United States Geological Survey's (USGS) database (http://earthexplorer.usgs. gov/). The downloaded images were the TM/ETM+ and the OLI with a resolution of $30 \mathrm{~m}$ which already had some standard pre-processing done by the USGS (https://landsat. usgs.gov/landsat-processing-details) which we considered to be sufficient for the intended analysis in this paper (Mwangi et al. 2017, Phiri \& Morgenroth 2017, Young et al. 2017). The images were chosen during the peak vegetation coverage period of summer (August) with minimal cloud coverage. An interval of approximately 8 years was selected as it was considered quite appropriate in tracking the dynamic change in landscape and proper management of the amount of data involved for analysis.

\section{Methodology}

Land use classification: In this paper, supervised classification using maximum likelihood algorithm was adopted using the ArcGIS 10.5 software which enabled us to categorize the land cover regions into 5 different categories such as grassland/shrub, highly vegetated, sparsely vegetated, barren soil and water region (Fig. 2 and Table 1). According to $\mathrm{Lu}$ \& Weng (2007), image classification comprises of several stages such as the selection of a suitable classification method, processing of post-classification images, and accuracy assessment of the map. A geometric image correction was first carried out to reduce the presence of displacement errors, atmospheric calibrations (atmospheric corrections) were also carried out to eliminate the presence of atmospheric effects on each of the image.

A stratified random sampling approach was applied for the assessment of the land use classification accuracy. To measure the extent of landcover accuracy, the Kappa test was applied due to its ability to not only analyse the diagonal elements but all the elements in the land use map confusion matrix (Rosenfield and Fitzpatric-Lins 1986). After the extraction of the land use map using ArcGIS, transfer matrix post-classification change technique was applied to analyse the dynamic changes of the land usage during the period of study.

In this research, the following equation was used;

$$
\% \text { Land Use Change }=\frac{\text { Area }_{\text {Y Year }}-\text { Area }_{i \text { year }(x+1)}}{\sum_{i=1}^{n} \text { Area }_{\text {i year } x}} \times 100
$$

Table 1: Description of the classified regions of the reserve.

\begin{tabular}{|ll|}
\hline Classified Regions & Description of the Classified Region \\
\hline Grassland/Shrubs & Mixed grasses and trees, shrub plants, agricultural land, aquatic vegetation and wetland vegetation. \\
Highly Vegetated & Healthy trees, afforested trees, mixed forest, \\
Sparsely Vegetated & Little to no vegetation land, uncultivated agricultural lands. \\
Barren Soil & Open soil with no vegetations, lakeshore free of vegetation, road networks, build-up areas. \\
Water & Lakes \\
\hline
\end{tabular}




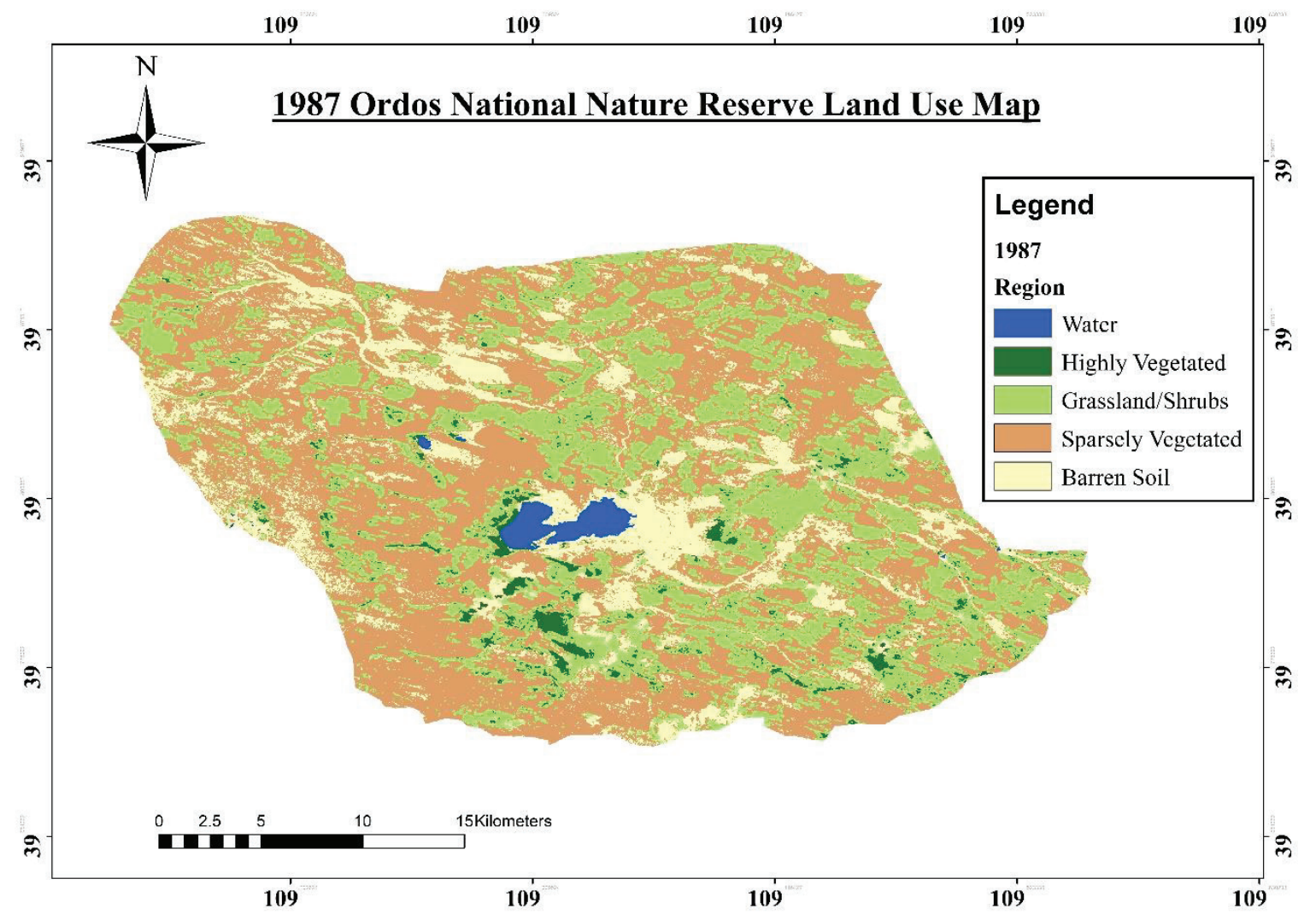

Fig. 2: Land use regions for Ordos catchment in 1987.

$\begin{aligned} \% \text { Land Use Coverage } & =\frac{\text { Area }_{\text {YYear } x}}{\sum_{i=1}^{n} \text { Area }_{\text {i year } x}} \times 100 \\ \text { Land Use Area Change } & =\text { Area }_{\text {i year }(x+1)}-\text { Area }_{i \text { year } x}\end{aligned}$

Where, Area $_{\mathrm{i} \text { Year } \mathrm{x}}$ is the land use area $i$ at the initial date; while Area $_{\mathrm{i} \text { Year }(x+1)}$ is the land-use area $i$ in the second period; $\sum_{\mathrm{i}=1}^{\mathrm{n}}$ Area $_{\mathrm{i} \text { year } \mathrm{x}}$ is the total land-use area at the initial date.

Land-use transition intensity analysis: To analyse the dynamics of land-use change, intensity and landscape patterns, the land-use transition intensity analysis was performed using the framework of (Aldwaik \& Pontius 2012). First, to quantify the land-use change over time, the transitional matrix was applied. A transitional matrix is a two-dimensional table in which land use categories at the earlier time interval are displayed in rows while categories at the later time intervals are displayed in columns (Mallinis et al. 2014, Aldwaik \& Pontius 2012). The transitional matrix in this paper was made for each interval (1987-1995, 1995-2003, 2003-2010 and 2010-2017). The method allows us to compute and compare the observed intensities of the changes in land use regions with uniform intensities. For each category gain or loss, the transition level analysis was used to compare the observed intensity of each transition with a hypothetical uniform transition that would occur if there was a uniform distribution of the transition between land use categories. Equations 4 and 5 were used to analyse the transition level analysis from an arbitrary category $i$ to the gaining category n (Aldwaik \& Pontius 2012, Pontius et al. 2013) hence identifying which land use category is intensively avoided or targeted by either the loss or gain of a particular category. Equation 4 calculated observed intensity $\mathrm{R}_{\text {tin }}$ of annual transition category $i$ to $\mathrm{n}$ for a given time interval. The observed intensity $R_{\text {tin }}$ was compared with the uniform intensity $\mathrm{W}_{\mathrm{tn}}$ calculated in equation 5 if the $\mathrm{R}_{\mathrm{tin}}>\mathrm{W}_{\mathrm{tn}}$, then gain of $\mathrm{n}$ is considered to target $i$.

$R_{\text {tin }}=\frac{\text { Size of annual transition from } i \text { to } n \text { during }\left(Y_{t}, Y_{t+1}\right)}{\text { size of } i \text { at } t}=\frac{C_{t i n} /\left(Y_{t+1}-Y_{t}\right)}{\sum_{j=1}^{J} C_{t i j}} 100 \%$

$W_{t n}=\frac{\text { size of annual gain of } n \text { during }\left(Y_{t}, Y_{t+1}\right)}{\text { size of not } n \text { att }}=\frac{\left[\left(\Sigma_{i=1}^{J} c_{t i n}\right)-c_{t n n}\right] /\left(Y_{t+1}-Y_{t}\right)}{\Sigma_{j=1}^{J}\left[\left(\Sigma_{i=1}^{J} c_{t i j}\right)-c_{t n j}\right]} 100 \%$

Where, $\mathrm{Y}_{\mathrm{t}}=$ Year at time point $\mathrm{t} ; \mathrm{t}=$ Index for the initial time point of interval $\left(\mathrm{Y}_{\mathrm{t}}, \mathrm{Y}_{\mathrm{t}+1}\right) ; \mathrm{i}=\mathrm{Index}$ for a category at 
an interval's initial time point; $\mathrm{j}=$ Index for a category at an interval's final time point; $\mathrm{n}=$ Index for the gaining category for the selected transition; $\mathrm{C}_{\mathrm{tij}}=$ Number of pixels that transition from category $i$ to category $j$ during the interval $\left(Y_{t}\right.$, $\left.\mathrm{Y}_{\mathrm{t}+1}\right) ; \mathrm{C}_{\mathrm{tin}}=$ Number of pixels that transition from category $i$ to category $n$ during the interval $\left(Y_{t}, Y_{t+1}\right) ; C_{t n n}=$ Number of pixels that remained category $\mathrm{n}$ during the interval $\left(\mathrm{Y}_{\mathrm{t}}\right.$, $\left.\mathrm{Y}_{\mathrm{t}+1}\right) ; \mathrm{J}=$ Number of categories.

Error analysis: To estimate the minimum errors in maps accounting for the difference in two maps from the same extent but different time intervals, (Aldwaik \& Pontius 2013) proposed a framework best suited for analysing the error. This error analysis method assesses the strength of the changes identified through the transition intensity analysis. The uniform hypothesis assumes a uniform change intensity with no temporal change in the map. In this analysis, two types of error were estimated (omission and commission error). The commission error indicates that the observed intensity of change $>$ the uniform hypothesized intensity. In the case of omission, the reverse is the case. Both errors are the difference between the observed change and uniform change. Hence, a larger omission and commission error indicates stronger evidence against the null hypothesis of uniform change which also means that there is a great possibility the difference in the maps are not necessarily due to classification errors but rather an actual change in the land use.

Commission error of Category $i$ at $t=E_{t i n}^{R}=\frac{\left(\sum_{i=1}^{J} C_{t i j}\right)\left(Y_{t+1}-Y_{t}\right)\left(R_{t i n}-W_{t n}\right)}{100 \%-\left(Y_{t+1}-Y_{t}\right) W_{t n}} 100 \%$

Commission of $i$ intensity at $t=\frac{E_{\text {tin }}^{R}}{C_{\text {tin }}} 100 \%$

Omission error of Category $i$ at $t=O_{t i n}^{R}=\frac{\left(\sum_{j=1}^{J} C_{t i j}\right)\left(Y_{t+1}-Y_{t}\right)\left(W_{t n}-R_{t i n}\right)}{100 \%-\left(Y_{t+1}-Y_{t}\right) W_{t n}} 100 \%$

Omission of category $i$ intensity at $t=\frac{o_{t i n}^{R}}{o_{t i n}^{R}+C_{\text {tin }}} 100 \%$
Where, $\mathrm{E}_{\text {tin }}^{\mathrm{R}}$, = number of elements that are observed transitions from category $i$ to category $n$ during interval $\left[\mathrm{Y}_{\mathrm{t}}, \mathrm{Y}_{\mathrm{t}+1}\right]$ but are hypothesized transitions from a non- $i$ category to category $n, \mathrm{O}_{\text {tin }}^{\mathrm{R}}=$ number of elements that are observed transitions from a non- $i$ category to category $n$ during the interval $\left[\mathrm{Y}_{\mathrm{t}}, \mathrm{Y}_{\mathrm{t}+1}\right]$ but are hypothesized transitions from a category $i$ to category $\mathrm{n}$.

Prediction analysis: In this paper, the prediction analysis was carried through the application of both Markov chain model and Cellular Automata (CA) methods using the CA-Markov model. Both the Markov and CA models are discrete dynamical models of time and status (Liu et al. 2008). The CA possess a powerful ability to simulate spatio-temporal changes of complex spatial systems (Sang et al. 2011), while the Markov model as earlier discusses focus mainly on the simulation and prediction of land cover changes. In this study both the CA and Markov model (CA-Markov model) was applied which is an integrated model that combines the spatial simulation ability of CA and the prediction ability of Markov to analyse and monitor the change evolution of the Ordos Basin. In this paper, based on both models we were able to simulate and predict the changes in the Ordos basin using IDRIS Selva (version 17.02) software under the CA-Markov Model (Eastman 2003).

Spatial pattern estimation: The analysis of the spatial pattern variations of the different regional landscape was used to reveal the dynamic changes on the wetland over time (YuhaiBao et al. 2011). For this study, we estimated the landscape metrics with one of the most popular spatial pattern analysis programs designed specifically for this purpose, FRAGSTAT Software (FRAGSTST 4.2) (Mcgarigal et al. 2000). The FRAGSTAT software offers a diverse choice of landscape metrics and has been greatly applied for the quantification of landscape structure. This approach is mainly used by ecologist and decision-makers in analysing the level of fragmentation of landscape and also to characterize the components of those landscapes. Considering the current situation of the Ordos basin's classification system, to analyse

Table 2: Landscape spatial pattern metrics details.

\begin{tabular}{|llll|}
\hline Metrics & Index & Index Name & Unit \\
\hline Patch & NP & Number of Patches & $\mathrm{n}(\mathrm{n} \geq 1)$ \\
& PD & Patch Density & $\mathrm{n} / 100 \mathrm{Ha}$ \\
& MPS & Mean Patch Size (Area Mean) & $\mathrm{Ha}$ \\
Edge & TE & Total Edge & $\mathrm{m}$ \\
& ED & Edge Density & $\mathrm{m} / \mathrm{Ha}$ \\
Shape & MSI & Mean Shape Index & Ha \\
Diversity & SHDI & Shannon's Diversity Index & - \\
& SHEI & Shannon's Evenness Index & - \\
\hline
\end{tabular}


the landscape pattern of the study site, we selected four metrics shown in Table 2. These metrics comprises of the Patch metrics, shape metrics, edge metrics, and diversity index.

\section{RESULTS}

\section{Land Use Change}

This study area was aggregated into different land-use regions as shown in Fig. 2. The kappa's coefficient accuracy assessment carried out on the classified images in this study recorded a value between 88 and $99 \%$ which indicates a very good agreement among the referenced data and the classified data. The result in Fig. 3 and 4A showed that over the years 1987 to 2017 significant changes occurred in the grassland region and the water region over the year 1987-2017. Within this period, the grassland region emerged the most dominant land cover type covering a total area of $338.75 \mathrm{~km}^{2}$ in 2017 $(52.88 \%)$ the sparsely vegetated region on the other hand also covered a considerable amount of the area covering $34.89 \%$ in 2017 . The proportion of the water and the highly vegetated region were the smallest compared to the other land cover regions. However, the water region on the other had experienced a dramatic decline in size from $1.13 \%$ to $0.36 \%$ during the year 1987-2017.

The upsurge of the grassland region is a clear indication of the increased anthropogenic activities in the region. Based on the examination of the other land use region, in 2017 all other regions except the grassland region showed a reduction in area. The area of the highly vegetated, barren soil and the sparsely vegetated region reduced by $1.73,10.14$, and $34.89 \%$ respectively (Fig. 3 ). The result of the transfer matrix showed that the conversion of all the land-use regions was a two-way conversion with one region changing to another land use region and vice versa.

Prediction analysis: From the 100 years prediction, the result in Fig. 4A and 4B showed that although the grassland region reduced by $5.29 \%$ in 2047 , it was still observed to be the most dominant region in the study site. while the grassland region reduced slightly in 2047 followed by a continuous increase in the area till 2117 , the sparsely vegetated region, on the other hand, showed a slight increase in area from 20172047 followed by a continuous decrease in area. The other land cover regions decreased continuously from 2017-2117.

Relationship between Bojiang lake and land-use change: Bojiang lake during the 30 years of study drastically reduced in size losing over $70 \%$ of its area to another region. Fig. 3 and 4 showed that while other regions reduced in size the grassland region contrasted in area change. The correlation and regression analysis carried out between Bojiang lake and the land cover regions showed that the changes in grassland region were statistically significant with $p$-values $<0.05$ while other regions proved to be not statistically significant. Based on this result of comparison between the change in Bojiang lake and the land cover change, and the effect of the variation

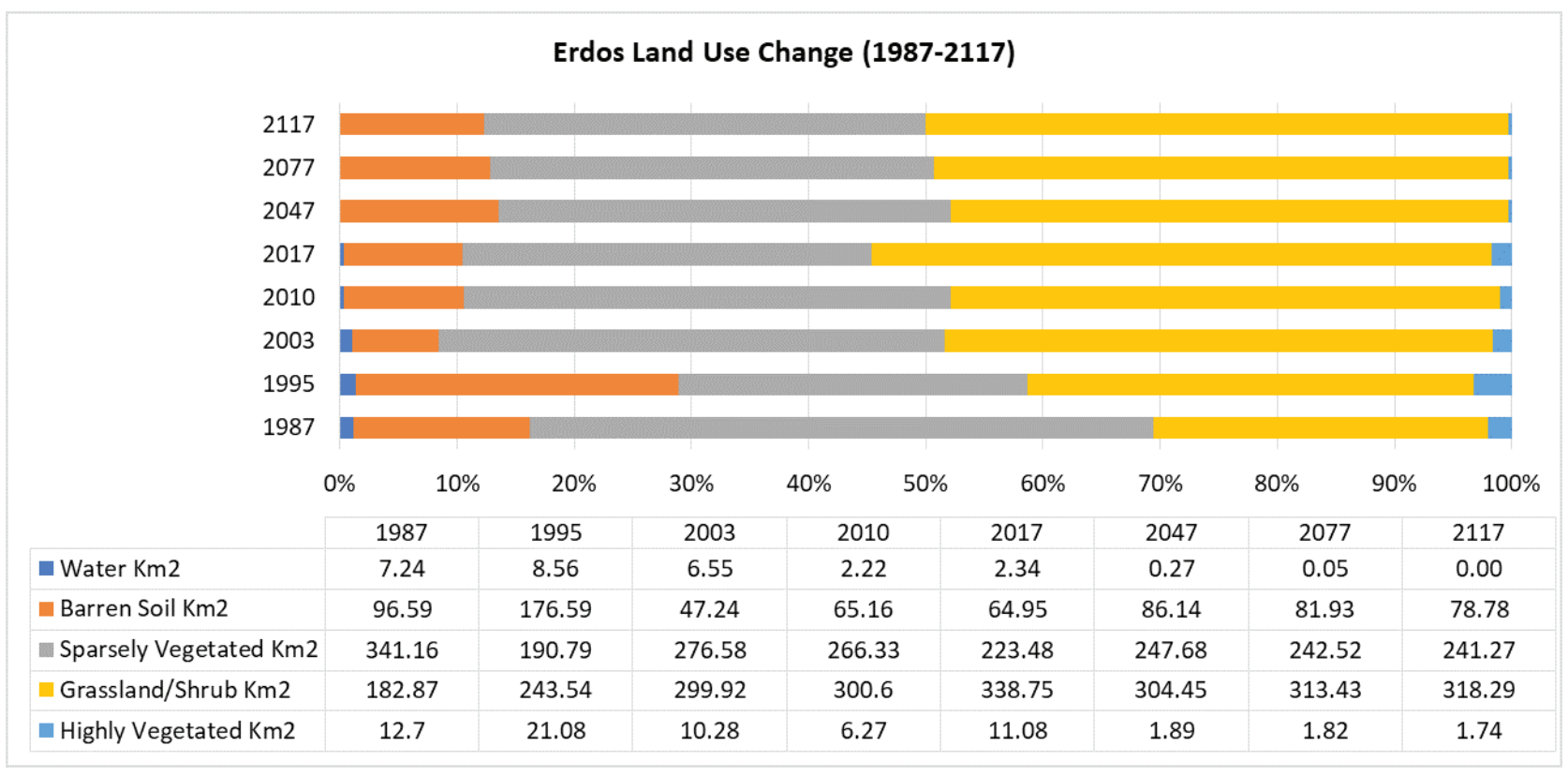

Fig. 3: Ordos Basin's regional area coverage from 1987 to 2117. 

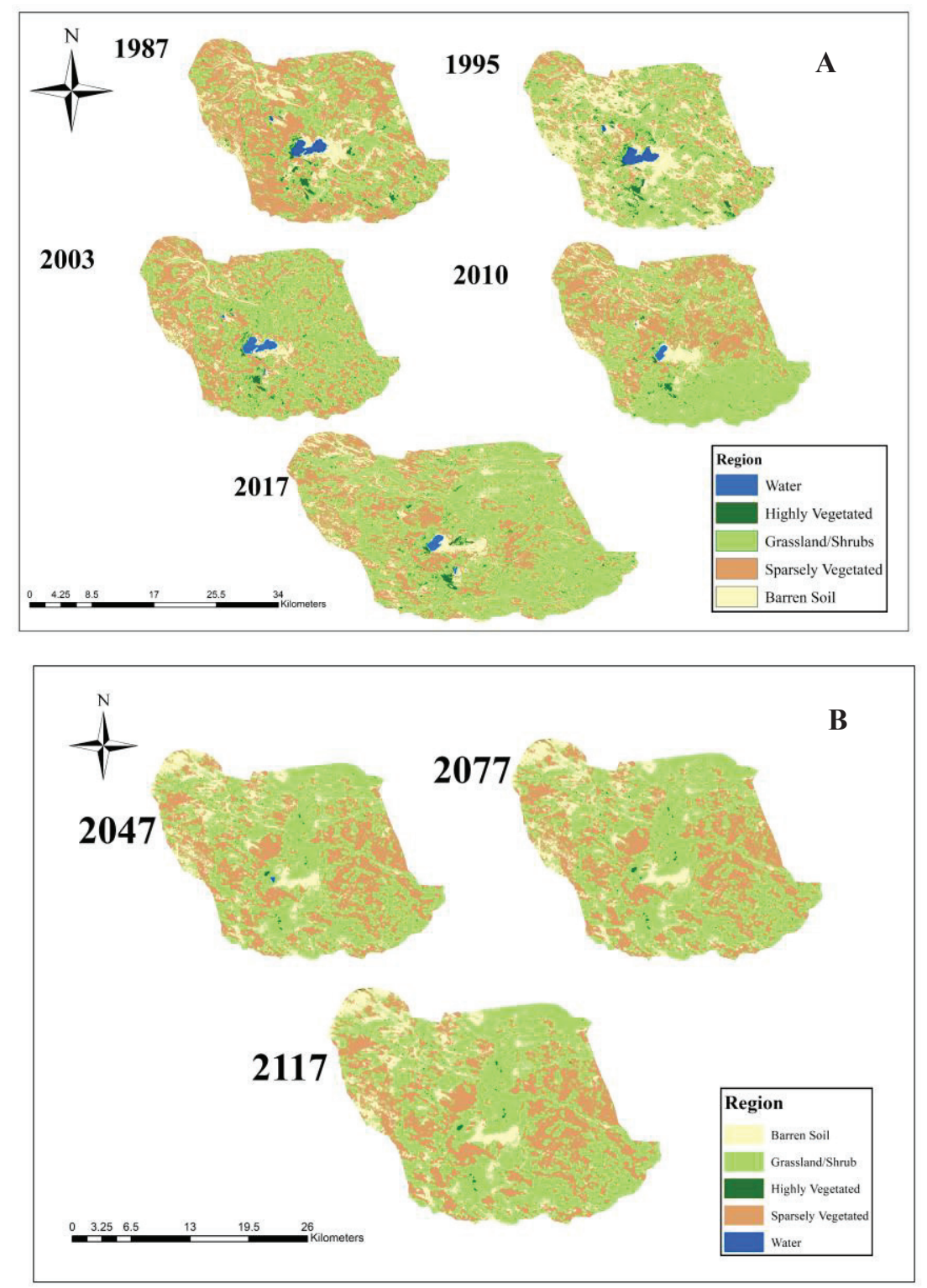

Fig. 4: Ordos Basin land-use change (A) 1987-2017, (B) 2047-2117.

between Bojiang lake and grassland region showed that the continuous increase in grassland region was closely related to the drastic reduction in the lake size.

Landscape pattern analysis: Landscape pattern of Ordos basin were analysed at the landscape and class level through four metrics (shape, patch, edge, and the diversity index). The parameter used were the Patch Density, Area Mean (Mean Patch size (MPS)), Edge Density (ED), Mean Shape Index (MSI), Shannon's diversity index and Shannon's evenness index (SHDI and SHEI). As shown in figure 5A, the result indicated changes in the entire landscape PD, MPS, ED, MSI,
SHDI and SHEI from 1987 to 2017. MSI (1.26 to 1.25), MPS (5.6 to $3.7 \mathrm{~km}^{2}$ ), SHDI (1.1 to 1.02 ) and SHEI (0.68 to 0.63 ) showed reduction while the PD (17.8 to 26.7) and ED (104.2 to 129.3 ) increased hence indicating heterogeneity towards an increased level of fragmentation in the landscape pattern of the Ordos Basin. From the result of the landscape pattern analysis of the 100 years predicted image, we observed that the heterogeneity continued indicating a continued increase in the fragmentation level with the ED (129.3 to 145.9), MPS (3.7 to 7.9), MSI (1.25 to 1.5 ) increased while, PD (26.7 to 12.6), SHDI (1.02 to 0.99$)$ and SHEI (0.638 to 0.62) reduced. 
At the class level shown in Figure 5B, all the regions showed different patterns compared to each other and from the whole pattern of landscape, the grassland and sparsely vegetated region both showed more aggregation over the 3-decade period of study.

Relationship between the landscape pattern change and the land-use change: The land-use changes share a relationship with the changes in the landscape pattern metrics. In Table 3, the coefficient value of each land cover regions represents the intensity of the effect where the consistency or difference in changes between the landscape metrics and the land cover regions are indicated with a positive or negative sign. With the regression analysis proving to be statistically significant having a p-value equal to 0.000 which is $<0.05$, the comparison of the effect between the land-use regions showed that the change in the sparsely vegetated region proved to possess the highest effect on PD (+5.3) and ED (14.14), this region had the most contrasting effect in the

Table 3: Intensity of land-use change in landscape patterns.

\begin{tabular}{|llllll}
\hline Metrics & Landscape Change & Class level change & P-Value \\
\hline PD & 8.9391 & grassland=1.03, sparsely veg=5.3, highly vegetated=1.2, barren soil=1.35, water=-0.014 & 0.000 \\
ED & 25.1631 & grassland=37.98, sparsely veg=14.14, highly vegetated=1.89, barren soil=-3.3, water=-0.35 & 0.000 \\
MPS & -1.873 & grassland=3.08, sparsely veg=-8.08, highly vegetated=-0.57, barren soil=-1.01, water=-15.01 & 0.000 \\
MSI & -0.0124 & grassland=-0.09, sparsely veg=0.07, highly vegetated=-0.05, barren soil=-0.018, water=-0.11 & 0.000 \\
\hline
\end{tabular}

Table 4: Land use transition between vegetative regions (Categories).

\begin{tabular}{|c|c|c|c|c|c|c|c|c|}
\hline \multicolumn{9}{|c|}{ Transition to Grassland } \\
\hline & \multicolumn{2}{|c|}{$1987-1995$} & \multicolumn{2}{|c|}{$1995-2003$} & \multicolumn{2}{|c|}{ 2003-2010 } & \multicolumn{2}{|c|}{ 2010-2017 } \\
\hline & \multicolumn{2}{|c|}{$\mathrm{UI}=3.05$} & \multicolumn{2}{|c|}{$\mathrm{UI}=3.57$} & \multicolumn{2}{|c|}{$\mathrm{UI}=4.68$} & \multicolumn{2}{|c|}{$\mathrm{UI}=4.92$} \\
\hline Losing Categories & $\mathrm{TI}$ & EI & $\mathrm{TI}$ & EI & $\mathrm{TI}$ & EI & $\mathrm{TI}$ & EI \\
\hline Barren Soil & 1.51 & 57.19 & 1.78 & 58.58 & 1.71 & 72.13 & 1.73 & 73.82 \\
\hline Highly Vegetated & $(5.06)$ & 52.56 & $(7.88)$ & 76.51 & $(8.52)$ & 67.00 & $(5.56)$ & 17.60 \\
\hline Sparsely Vegetated & $(3.46)$ & 15.98 & $(4.94)$ & 38.80 & $(5.16)$ & 13.81 & $(5.73)$ & 21.67 \\
\hline Water & 0.00 & 99.94 & 0.28 & 94.23 & 0.55 & 91.82 & 0.10 & 98.69 \\
\hline \multicolumn{9}{|c|}{ Transition to Highly Vegetated } \\
\hline & \multicolumn{2}{|c|}{$1987-1995$} & \multicolumn{2}{|c|}{$1995-2003$} & \multicolumn{2}{|c|}{ 2003-2010 } & \multicolumn{2}{|c|}{$2010-2017$} \\
\hline & \multicolumn{2}{|c|}{$\mathrm{UI}=0.28$} & \multicolumn{2}{|c|}{$\mathrm{UI}=0.09$} & \multicolumn{2}{|c|}{$\mathrm{UI}=0.06$} & \multicolumn{2}{|c|}{$\mathrm{UI}=0.16$} \\
\hline Losing Categories & $\mathrm{TI}$ & EI & $\mathrm{TI}$ & EI & $\mathrm{TI}$ & EI & $\mathrm{TI}$ & EI \\
\hline Barren Soil & 0.10 & 65.75 & 0.01 & 91.62 & 0.02 & 60.08 & $(0.30)$ & 48.75 \\
\hline Grassland & $(0.85)$ & 68.23 & $(0.20)$ & 57.25 & $(0.11)$ & 46.34 & $(0.23)$ & 31.09 \\
\hline Sparsely Vegetated & 0.04 & 87.61 & 0.01 & 88.02 & 0.01 & 81.23 & 0.04 & 72.38 \\
\hline Water & 0.13 & 55.11 & $(0.15)$ & 42.56 & 0.02 & 68.40 & 0.02 & 87.42 \\
\hline \multicolumn{9}{|c|}{ Transition to Sparsely vegetated } \\
\hline & \multicolumn{2}{|c|}{$1987-1995$} & \multicolumn{2}{|c|}{$1995-2003$} & \multicolumn{2}{|c|}{ 2003-2010 } & \multicolumn{2}{|c|}{ 2010-2017 } \\
\hline & \multicolumn{2}{|c|}{$\mathrm{UI}=1.82$} & \multicolumn{2}{|c|}{$\mathrm{UI}=4.51$} & \multicolumn{2}{|c|}{$\mathrm{UI}=4.48$} & \multicolumn{2}{|c|}{$\mathrm{UI}=3.15$} \\
\hline Losing Categories & $\mathrm{TI}$ & EI & TI & EI & TI & EI & $\mathrm{TI}$ & EI \\
\hline Barren Soil & $(1.91)$ & 5.79 & $(7.79)$ & 65.87 & 3.64 & 25.33 & $(3.58)$ & 15.40 \\
\hline Grassland & $(1.92)$ & 6.34 & 2.59 & 53.75 & $(4.83)$ & 10.55 & 3.15 & 0.17 \\
\hline Highly Vegetated & 0.59 & 70.60 & 0.82 & 87.53 & 0.85 & 86.23 & 0.15 & 96.24 \\
\hline Water & 0.00 & 99.93 & 0.42 & 93.82 & 0.07 & 98.92 & 0.03 & 99.26 \\
\hline
\end{tabular}

$\mathrm{UI}=$ Uniform intensity (\% of other categories, excluding the concerned category); TI= Transition intensity (Parentheses values indicate targeted categories for loss or gain while non-parenthesis indicates the categories was avoided by the change); EI=Error Intensity (Bold values are omission, non-bold values are commission). 

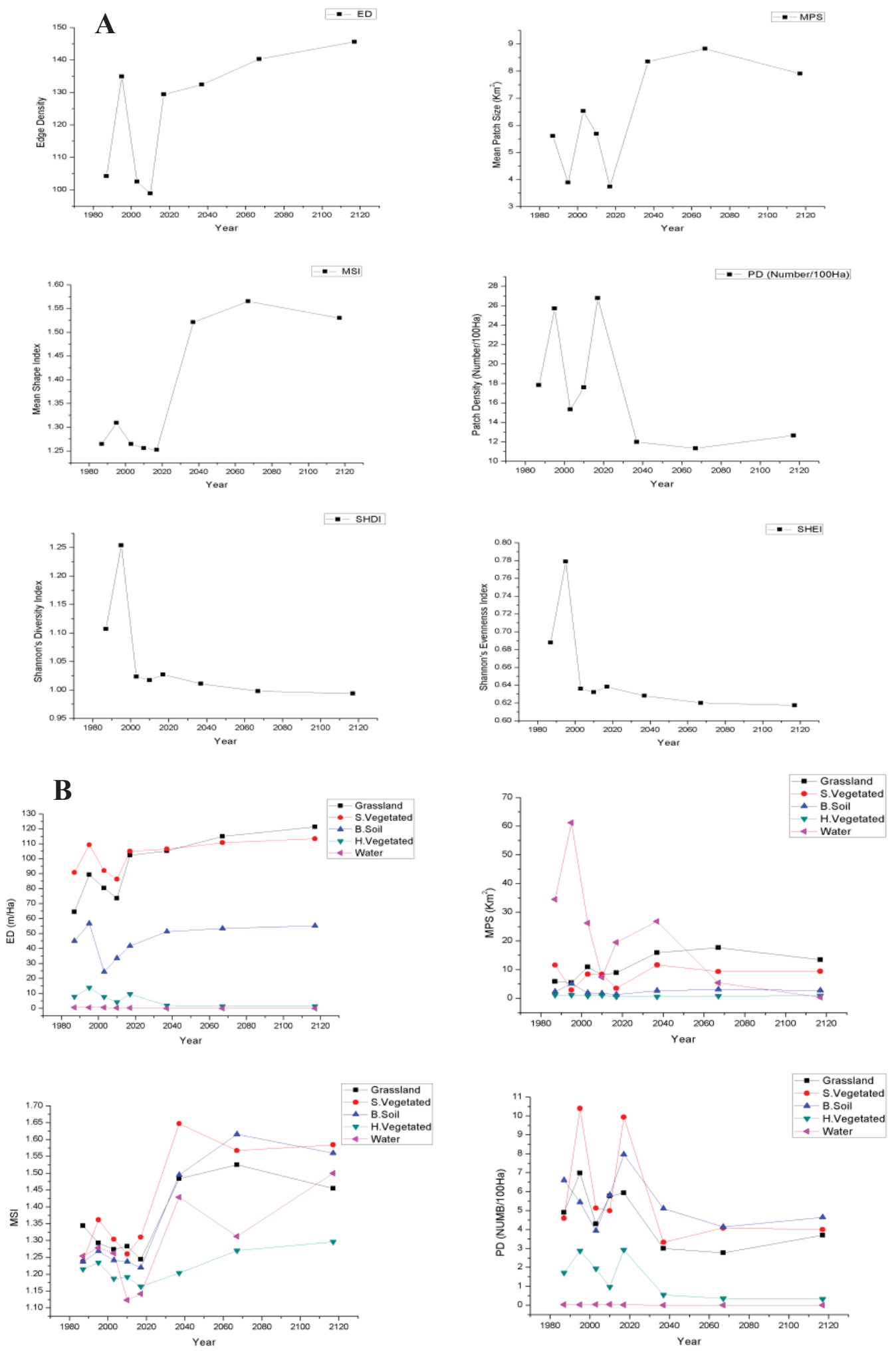

Fig. 5: Landscape pattern change (A) landscape level, (B) class level. 
MPS (-8.08). Grassland region, on the other hand, exhibited a significant effect on ED (+37.98) and MPS (+3.08) with its most contrasting effect recorded in MSI (-0.09). The most opposite effect observed was the on water region with its effect on metrics change exhibited in MPS (-15.01) and MSI (-0.11). A regression analysis carried out between Bojiang lake area change and the landscape pattern metrics change proved not to be statistically significant but the reduction in size confirms the opposite effect the water region had on the landscape metrics.

\section{Transition Between Grassland and Vegetated Region}

The result of our analysis suggested that the grassland region mainly expanded into the sparsely vegetated and highly vegetated regions all through the study period from 19872017 (Table 4). The time intervals (1987-1995, 1995-2003, 2003-2010 and 2010-2017), were categorized based on the changes in the lake area, for instance, the year 1987-1995 was chosen because the lake area increased significantly during this period, from 1995-2003, the lake started reducing gradually, however, during 2003-2010 lost more than half of its area and lastly from 2010-2017, the lake area increased slightly due to the artificial water supply.

During the four intervals, there was an intensive systematic gain of the grassland region from both the sparsely vegetated and highly vegetated region (Fig. 6). An example of this transition is during the second interval (1995-2003) the annual intensity gain of the grassland region from both highly and sparsely vegetated regions were 7.88 and $4.94 \%$ respectively of the size of both regions in 1995 (Table 4) compared to the uniform intensity of $3.57 \%$ (of the landscape that was not grassland in 1995). This change implies that the grassland region gained from the highly vegetated region over 2 times more than the rate it would be expected to gain uniformly (from all land use categories). The annual intensity is higher for highly vegetated than the sparsely vegetated region in all intervals except the last interval which means the annual intensity of highly vegetated region was higher than the uniform intensity. It was also observed that the highly vegetated region consistently targeted the grassland region in all intervals while the sparsely vegetated region only targeted the grassland region in two intervals (1987-1995 and 20032010). Hence indicating that the grassland region may be mainly a transitional land use for both the highly vegetated and sparsely vegetated region.

The error intensity (EI) in Table 4 shows strong evidence that the grassland region gained intensively from both sparsely and highly vegetated regions. Based on the deviations from uniform intensity observed in the study, it implies that there was a real temporal transition between grassland region and the other vegetated regions (sparsely and highly vegetated). An example is the commission error intensity for the transition from grassland to the highly vegetated region during 1995-2003 which was $76.51 \%$ (Table 4) this high percentage of error intensity shows strong evidence against the uniform change hypothesis. This error analysis does not provide a threshold of how large an observed intensity's deviation from uniform intensity should be suitable for a real change, this is due to the non-precise nature of the actual map classification error like in the case of our study (Aldwaik \& Pontius 2013, Pontius et al. 2013, Enaruvbe \& Pontius 2015).

$\mathrm{UI}=$ Uniform intensity (\% of other categories, excluding the concerned category); TI= Transition intensity (Parentheses values indicate targeted categories for loss or gain while non-parenthesis indicates the categories was avoided by the change); EI= Error Intensity (Bold values are omission, non-bold values are commission).

Transition intensity for predicted image: From the 100year prediction analysis carried out (2017-2117), it was observed the grassland region intensive gain consistently targeted the highly vegetated. The sparsely vegetated region was only slightly targeted in the first interval. During the three intervals (2017-2047, 2047-2077 and 2077-2117). An example of this transition is during the interval from 20172047, the annual intensity gain of the grassland region from the highly vegetated region was $2.27 \%$ compared to the uniform intensity of $1.29 \%$. The error intensity (EI) ranging from $52-76.7 \%$ in Table 5 at all intervals showed strong evidence that the grassland region gained intensively from the highly vegetated region.

Transition between the vegetated region and the water region: Water region which showed a continuous reduction in size over the cause of this study period (1987-2017), was directly or indirectly influenced by the changes in other land cover region. From the transition analysis results in Table 4 , it was observed that the gains in all vegetated region did not target the water region except for the highly vegetated region in one interval (1995-2003) with a transition intensity of $0.15 \%$ slightly higher than the uniform intensity of $0.09 \%$. The transition to Barren Soil region on the other hand consistently targeted the water and sparsely vegetated region at 3 intervals (1995-2017). The transition intensity for the water region during 1995-2003 and 2003-2010 was more than 10 times the uniform intensity of each interval. This, however, indicates that although the vegetated region did not directly target the water region in their transition, they, however, had an indirect impact on the change in the water region.

Transition intensity for predicted image: From 20172117 , the grassland region compared to the other vegetated 
regions gained consistently from the water region in all intervals 2017-2047, 2047-2077 and 2077-2117 (Fig. 7). The highly vegetated region, on the other hand, gained a bit from the water region only in the first interval (2017-2047). The annual transition gain of the grassland region during 2017-2117 from water region in all intervals was 2.23, 2.66 and 2.39 compared to the uniform of $1.29,0.27$ and 0.20 respectively. The error intensity, on the other hand, showed strong evidence that the grassland region gained a subsistent amount from the water region with a very high Error index value ranging between 68.57 and $99.59 \%$.

$\mathrm{UI}=$ Uniform intensity (\% of other categories, excluding the concerned category); $\mathrm{TI}=$ Transition intensity (Parentheses values indicate targeted categories for loss or gain while
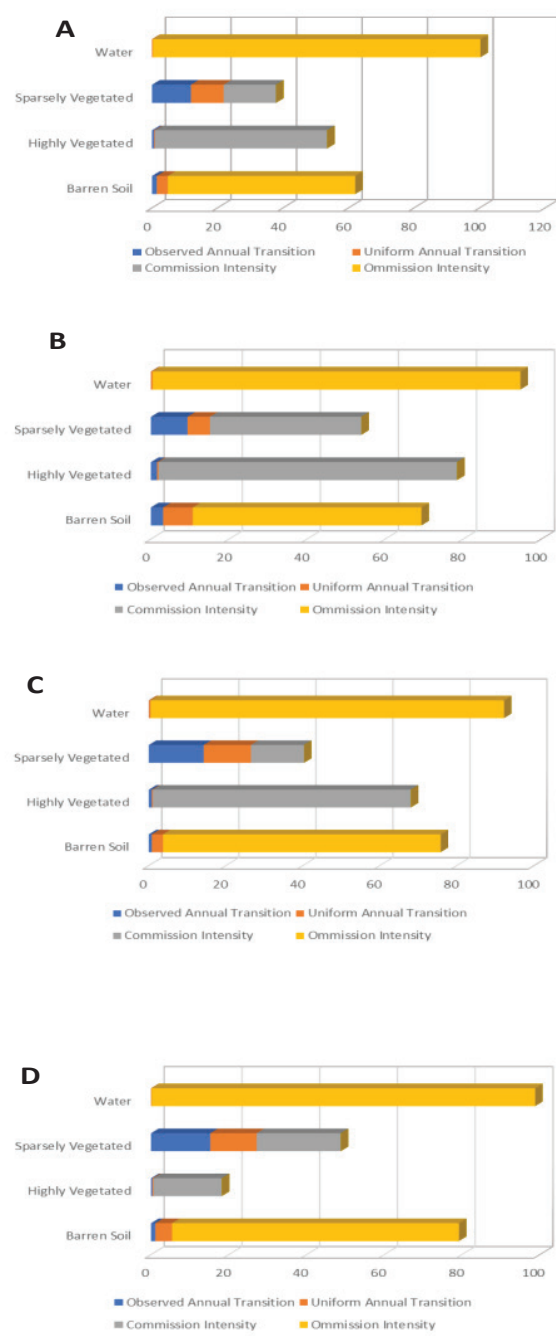

Fig. 6: Transition to grassland (A)1987-1995, (B) 1995-2003, (C) 2003-2010, (D) 2010-2017.
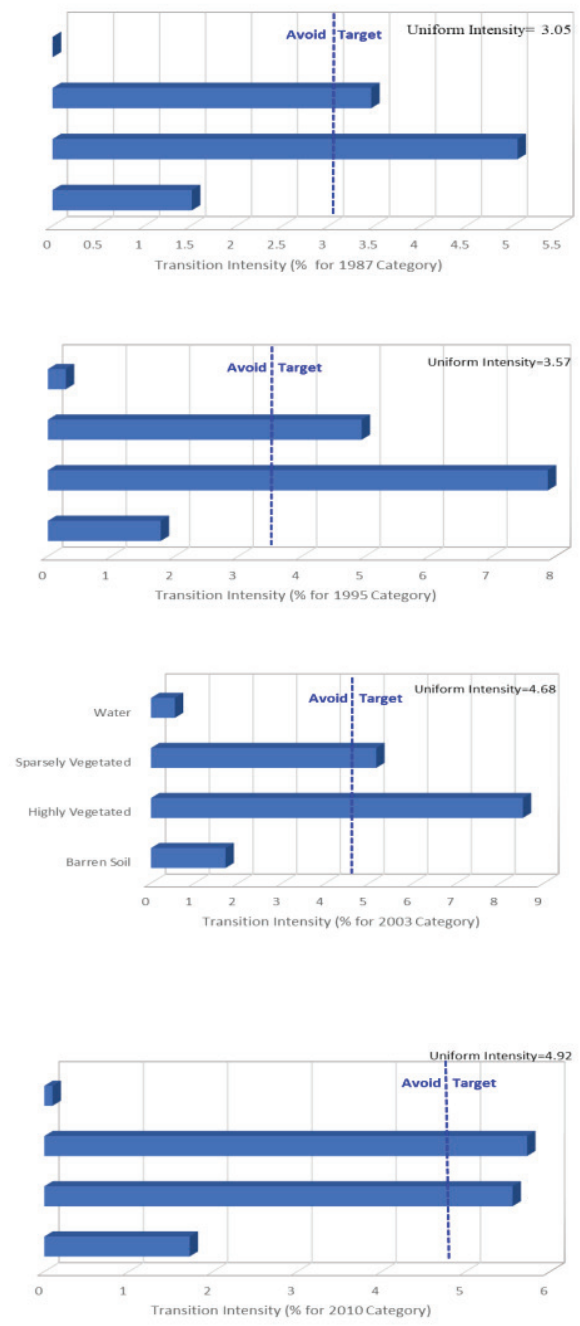

non-parenthesis indicates the categories was avoided by the change); EI= Error Intensity (Bold values are omission, non-bold values are commission).

\section{Land-Use Change Trend Analysis}

The land-use changes between 1987 and 2017 were investigated in this paper. The changes in the Ordos basin during the 3-decade duration of study made a significant influence on the land use structure. Significant changes in each land cover region occurred all through the study period with the grassland and sparsely vegetated region occupying a considerable amount of the study region. While the highly vegetated region, barren soil and the sparsely vegetated region were experiencing inconsistency in area change, the grassland 
region continuously showed a significant increase in size, the water region, on the other hand, proved otherwise. Most land use categories in the study region underwent swap change though the study period. A swap change depicts changes in land cover regions (loss) occurring in one location while an equal gain in another location (Pontius et al. 2004, Yuan et al. 2016, Zaehringer et al. 2015). The last row of Table 6 reveals that the swap changes from 1995-2017 accounted for more than $50 \%$ of the overall land-use change in all three intervals, the same applies to the predicted images 2017-2117 (Table $7)$. This indicates that land-use change in the Ordos basin was very dynamic during those periods which were followed by a high rate of land use categories relocations. Higher swap change percentage indicates an overall change more than the net change and reveals the significance of detailed analysis of land cover change beyond the net change (Yuan et al. 2016).
From the swap analysis, it was observed that while other regions were experiencing loss in the area the grassland region continued to gain all through the study period in all intervals. For example, for the 1995-2003 interval, while the water and highly vegetated region had a loss rate of (2 and $10 \mathrm{~km}^{2} /$ year), the grassland, barren and sparsely vegetated region had a gross gain of $\left(56,128\right.$ and $140 \mathrm{~km}^{2} /$ year $)$. The transition matrix also explained that the changes in the regions which reveal that although the grassland region continuously increased in size all through the study, it targeted other land cover regions like the highly vegetated region and sparsely vegetated region during its area change. Based on the analysis of the predicted image (2017-2117), the grassland region also continued to dominate in area coverage occupying about $50 \%$ of the total area. This continuous increase in the grassland region and inconsistency in the other regions in-

Table 5: Land use transition between Vegetative Regions (Categories).

\begin{tabular}{|c|c|c|c|c|c|c|c|c|}
\hline \multicolumn{9}{|c|}{ Transition to Grassland } \\
\hline & \multicolumn{2}{|c|}{$1987-2017$} & \multicolumn{2}{|c|}{$2017-2047$} & \multicolumn{2}{|c|}{$2047-2077$} & \multicolumn{2}{|c|}{$2077-2117$} \\
\hline & \multicolumn{2}{|c|}{$\mathrm{UI}=0.57$} & \multicolumn{2}{|c|}{$\mathrm{UI}=1.29$} & \multicolumn{2}{|c|}{$\mathrm{UI}=0.27$} & \multicolumn{2}{|c|}{$\mathrm{UI}=0.20$} \\
\hline Losing Categories & TI & EI & TI & EI & TI & EI & TI & EI \\
\hline Barren Soil & 0.36 & 40.22 & $(1.37)$ & 9.14 & $(0.30)$ & 10.51 & $(0.23)$ & 12.12 \\
\hline Highly Vegetated & $(1.56)$ & 76.70 & $(2.27)$ & 70.36 & $(0.83)$ & 73.74 & $(0.39)$ & 52.03 \\
\hline Sparsely Vegetated & $(0.58)$ & 3.63 & 1.22 & 9.46 & 0.25 & 6.64 & 0.19 & 5.56 \\
\hline Water & 0.03 & 95.57 & $(2.23)$ & 68.57 & $(2.66)$ & 97.81 & $(2.39)$ & 99.59 \\
\hline \multicolumn{9}{|c|}{ Transition to Highly Vegetated } \\
\hline & \multicolumn{2}{|c|}{$1987-2017$} & \multicolumn{2}{|c|}{$2017-2047$} & \multicolumn{2}{|c|}{$2047-2077$} & \multicolumn{2}{|c|}{$2077-2117$} \\
\hline & \multicolumn{2}{|c|}{$\mathrm{UI}=0.05$} & \multicolumn{2}{|c|}{$\mathrm{UI}=0.01$} & \multicolumn{2}{|c|}{$\mathrm{UI}=0.00$} & \multicolumn{2}{|c|}{$\mathrm{UI}=0.00$} \\
\hline Losing Categories & $\mathrm{TI}$ & EI & $\mathrm{TI}$ & EI & TI & EI & $\mathrm{TI}$ & EI \\
\hline Barren Soil & 0.02 & 54.10 & 0.01 & 30.86 & 0.00 & 48.04 & 0.00 & 19.57 \\
\hline Grassland & $(0.08)$ & 32.55 & $(0.01)$ & 27.10 & $(0.00)$ & 41.51 & $(0.00)$ & 29.91 \\
\hline Sparsely Vegetated & 0.02 & 56.40 & 0.00 & 52.06 & 0.00 & 70.33 & 0.00 & 48.47 \\
\hline Water & 0.00 & 95.58 & $(0.05)$ & 79.67 & 0.00 & 100.00 & 0.00 & 100.00 \\
\hline \multicolumn{9}{|c|}{ Transition to Sparsely vegetated } \\
\hline & \multicolumn{2}{|c|}{$1987-2017$} & \multicolumn{2}{|c|}{$2017-2047$} & \multicolumn{2}{|c|}{ 2047-2077 } & \multicolumn{2}{|c|}{$2077-2117$} \\
\hline & \multicolumn{2}{|c|}{$\mathrm{UI}=1.57$} & \multicolumn{2}{|c|}{$\mathrm{UI}=1.15$} & \multicolumn{2}{|c|}{$\mathrm{UI}=0.14$} & \multicolumn{2}{|c|}{$\mathrm{UI}=0.13$} \\
\hline Losing Categories & $\mathrm{TI}$ & EI & TI & EI & TI & EI & $\mathrm{TI}$ & EI \\
\hline Barren Soil & 1.47 & 10.94 & 0.80 & 39.77 & $(0.20)$ & 34.14 & $(0.18)$ & 28.82 \\
\hline Grassland & (1.63) & 7.42 & $(1.24)$ & 10.65 & 0.12 & 14.17 & 0.12 & 10.02 \\
\hline Highly Vegetated & 0.39 & 85.07 & 0.67 & 51.80 & $(0.17)$ & 19.17 & 0.08 & 43.44 \\
\hline Water & 0.00 & 99.94 & 0.04 & 97.41 & 0.00 & 100.00 & 0.00 & 100.00 \\
\hline
\end{tabular}

$\mathrm{UI}=$ Uniform intensity (\% of other categories, excluding the concerned category); TI=Transition intensity (Parentheses values indicate targeted categories for loss or gain while non-parenthesis indicates the categories was avoided by the change); EI=Error Intensity (Bold values are omission, non-bold values are commission). 
dicates an increase in anthropogenic activities in this region.

\section{DISCUSSION}

\section{Relationship Between the Land Use change and Spatial Pattern}

In recent years, with the development and utilization of coal and oil and gas resources and the continuous development of local economy, the status of its infrastructure has been greatly improved, and road traffic and power facilities have begun to take shape. Agriculture and aquaculture are still the main industries of the people in the region. The industrial industries are mainly petrochemical, chemical, brick, carpet, cement, coal mining, etc. The local residents are mainly engaged in agriculture and aquaculture, and some labourers are engaged in coal mining and oil production. Transportation and other industries. However, the continuous exploitation of coal mines and oil and the rapid development of the agricultural industry not only led to lead to an increase in regional water demand, but it also increased landscape fragmentation. From this study, the landscape pattern and the land-use regions in this study showed a strong relationship. The result from the OLS regression model used to examine the level of accuracy of changes in the landscape metrics and the intensity of the effect each land-use changes has on the landscape pattern showed that the major changes in the landscape pattern had
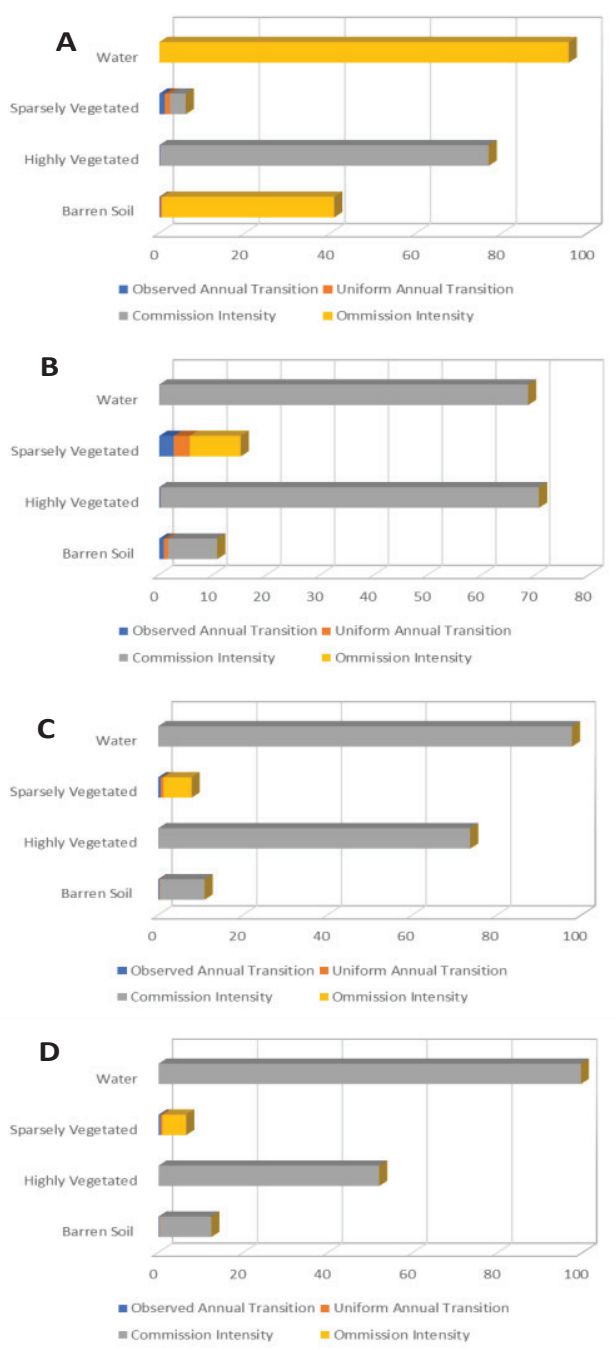
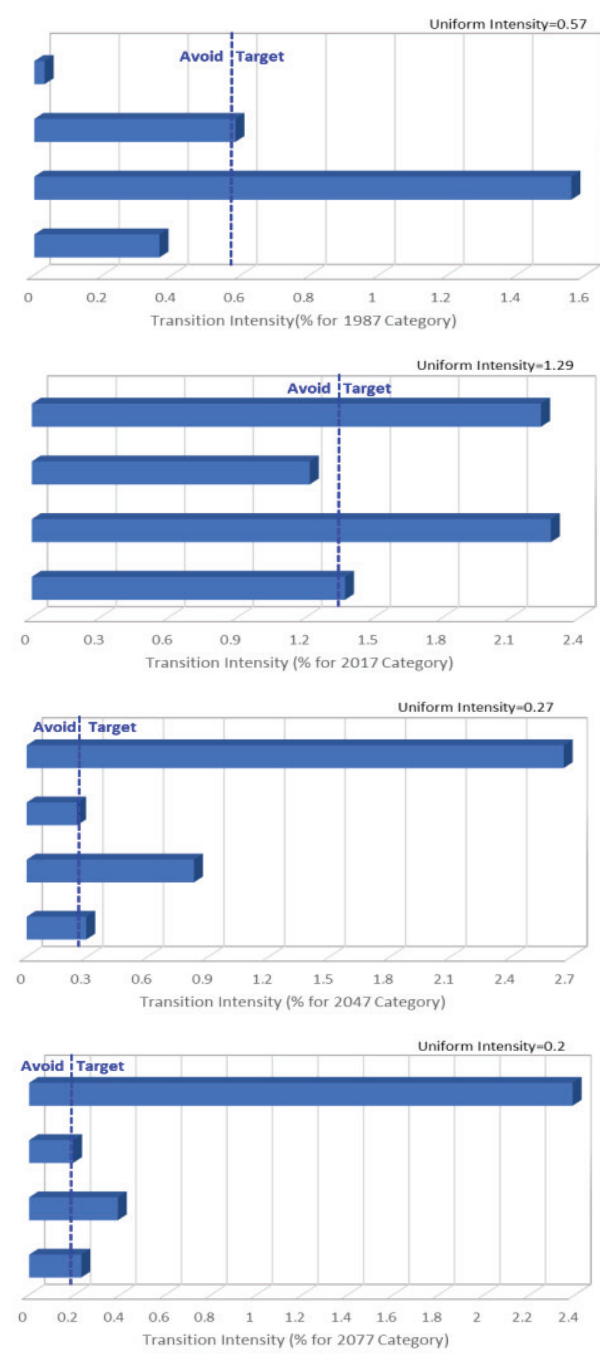

Fig. 7: Transition to grassland (A)1987-2017, (B) 2017-2047, (C) 2047-2077, (D) 2077-2117. 
a strong relationship with all four regions (grassland, highly vegetated, sparsely vegetated, and barren soil region) except the water region. Hence the growth experienced in the grassland region which was possibly as a result of the increase in agricultural activities was closely related to the increased heterogeneity and fragmentation of the whole landscape. The result from this study is similar to the result of ( $\mathrm{Yu} \& \mathrm{Ng}$ 2006, Hashem Dadashpoor et al. 2019) who believed that in the human landscape, changes in agriculture and garden can lead to fragmentation of the landscape. Several factors can be responsible for the increase in fragmentation an example is increased urbanization, economic development, agriculture and garden land. As of the case of this study, all of the above-mentioned factors are believed to have played a role in the increased fragmentation experienced in the study region.

\section{Effects of Ecological Restoration Measures on the Vegetation Transpiration}

Combining the characteristics of land-use change in the basin over the past decade, the impact of ecosystem type conversion was analysed. The Bojiang Lake basin located in the transition zone between grassland and desertified grassland. The vegetation is sparse, grassland is the main ecosystem, followed by cultivated land and forest land (sparsely vegetated and highly vegetated region respectively). Based on the image classification in this study, the basin mainly includes grassland (grassland, meadow, agricultural land, shrub forest etc.), highly vegetated region (mainly the broad forest), water region and the barren soil. Among the major type of ecosystem, the area of grassland, sparsely vegetated, and lake area changed the most mainly due to the implementation of relevant policies such as ecological forest construction in Inner Mongolia Autonomous Region. The Ordos began to implement a ban on grazing, returning farmland to forests and grassland in 2000. With the construction of the project, the area of artificial vegetation in Ordos city increased significantly as we can see in the changes in the grassland region from 182.8 in 1987 to 338.7 in 2017 (Fig. 3). After the enclosure, the vegetation mainly depends on precipitation and soil water growth, and the trees need to be irrigated at the initial stage of planting. After a period of growth, they start to draw groundwater to maintain growth. The local precipitation of around $364 \mathrm{~mm}$ cannot fully guarantee the water demand for tree growth, and it is necessary to use groundwater, and the water for ecological construction is increasing sharply. Although the increase of vegetation will play a positive role in preventing soil erosion and protecting the ecological environment, vegetation will have a significant impact on the redistribution of surface water and groundwater through canopy interception and water and will increase water volume due to transpiration. Consumption, thereby reducing the amount of water entering the lake. Vegetation has a significant role in preventing wind, preventing soil erosion and conserving water sources. However, it increases the amount of ecological water consumption in small areas and, to a certain extent, reduces the amount of lake water entering the lake, but the overall impact is very small.

\section{Effect of Population and Urbanization on Lake Reduction}

The residents living in the reserve and 18 civil wells were discovered. The survey found that the villagers' daily water and agricultural water are taken from the groundwater, which will have a certain impact on the water volume change of the wetlands in the gull reserve. There have been many large wells built since 2000. These large wells are mostly rectangular, about 100-200 m long, about $30 \mathrm{~m}$ wide, with a gentle slope and simple engineering. In recent years, with the development and utilization of coal and oil and gas resources and the continuous development of local economy, the status of its infrastructure has been greatly improved, and road traffic and power facilities have begun to take shape. Agriculture and aquaculture are still the main industries of the people in the region. The industrial industries are mainly

Table 6: Annual land-use change ( $\mathrm{km}^{2} /$ year) during the four intervals.

\begin{tabular}{|lllllllllllll|}
\hline & \multicolumn{1}{l}{$1987-1995$} & \multicolumn{3}{c}{$1995-2003$} & \multicolumn{2}{c}{$2003-2010$} & \multicolumn{3}{c|}{$2010-2017$} \\
\hline Change & Total & Net & Swap (\%) & Total & Net & Swap (\%) & Total & Net & Swap (\%) & Total & Net & Swap (\%) \\
\hline Barren Soil & 138 & 82 & 40.6 & 144 & -128 & 11.1 & 52 & 16 & 69.2 & 52 & 0.5 & 99 \\
Grassland & 161 & 62 & 61.5 & 170 & 56 & 67.1 & 223 & 0.4 & 99.8 & 196 & 38 & 80.6 \\
Highly Vegetated & 21 & 8 & 61.9 & 19 & -10 & 47.4 & 9 & -4 & 55.5 & 10 & 4 & 60 \\
Sparsely Vegetated & 240 & -153 & 36.25 & 242 & 83 & 65.7 & 237 & -9 & 96.2 & 208 & -43 & 79.3 \\
Water & 2 & 1 & 50 & 3 & -2 & 33.3 & 4 & -4 & 2.03 & 0 & 0.2 & 66.7 \\
Overall Change & 281 & 153 & 45.6 & 288 & 140 & 51.4 & 263 & 17 & 93.5 & 233 & 43 & 81.5 \\
\hline
\end{tabular}

Total $=$ gross gain + gross loss; Net $=$ gross gain - gross loss; Swap $(\%)=(($ Total - Net $) /$ Total $) \times 100$ 
Table 7: Annual land-use change $\left(\mathrm{km}^{2} /\right.$ year $)$ during the four predicted year intervals.

\begin{tabular}{|c|c|c|c|c|c|c|c|c|c|c|c|c|}
\hline \multirow[b]{2}{*}{ Change } & \multicolumn{3}{|c|}{$1987-2017$} & \multicolumn{3}{|c|}{$2017-2047$} & \multicolumn{3}{|c|}{$2047-2077$} & \multicolumn{3}{|c|}{$2077-2117$} \\
\hline & Total & Net & Swap (\%) & Total & Net & Swap (\%) & Total & Net & Swap (\%) & Total & Net & Swap (\%) \\
\hline Barren Soil & 108.1 & 31 & 71.3 & 106 & 22 & 79.2 & 22 & -4 & 81.8 & 24 & -3 & 87.4 \\
\hline Grassland & 260.2 & -159 & 39 & 269 & -37 & 86.2 & 45 & 9 & 80 & 48 & 5 & 89.7 \\
\hline Highly Vegetated & 17.6 & 1.9 & 89.3 & 12 & -8 & 33.3 & 1 & -0 & 94 & 1 & -0 & 92 \\
\hline Sparsely Vegetated & 272.7 & 120 & 56 & 263 & 25 & 90.5 & 37 & -5 & 86.5 & 44 & -1 & 97.7 \\
\hline Water & 5.3 & 4.9 & 7.5 & 2 & -2.1 & 3.7 & 0 & -0 & 0 & 0 & -0 & 0 \\
\hline Overall Change & 331.9 & 159 & 52.2 & 326 & 47 & 85.6 & 52 & 9 & 82.7 & 58 & 5 & 91.4 \\
\hline
\end{tabular}

Total= gross gain + gross loss; Net= gross gain - gross loss; Swap $(\%)=(($ Total - Net $) /$ Total $) \times 100$

petrochemical, chemical, coal mining, etc. The local residents are mainly engaged in agriculture and aquaculture, and some of the labour force is engaged in coal mining, oil production and transportation industries. However, the continuous exploitation of coal and oil and the development of the industry will lead to an increase in regional water demand. At the same time, surface subsidence and water-conducting fissures generated by coal mining exploration will affect the protected flow area and runoff direction. Therefore, the coal mining industry enterprises and the sources of agricultural and domestic water are related to the reduction of water in protected areas.

The water consumption of industrial and agricultural waters in the basin has reduced the surface runoff and the groundwater level in the basin through the demand for surface runoff and groundwater resources. However, at present, there are fewer and fewer populations in the Neighbouring Nature Reserve and the surrounding areas. The number of people has increased year by year, and the resident population has declined year by year, accounting for only $21 \%$ of the total population (Fig. 8). Therefore, observations from long-term data show that activities such as human production and living activities and industrial and agricultural exploitation in the basin have certain impacts on the water table and lake water volume in the basin. But the long-term impact is small.

Effect of weather conditions: Over the years, climate factors were considered to be the primary driving force for this reduction due to the slight increase in human activities. Research by He et al. (1992), pointed out that a contributing factor to the reduction in the water level in the study site was the sediment-trapping dams built on the rivers after 2000 which intercepted the direct flow of water into the lake including other factors such as increased ecotourism, domestic use of water and so on. All of these coupled with the decrease in precipitation and increased temperature all play a role in the reduction in the water level. Kang Liang's Study (Kang 2017) proved that increased human activities were the main factor for the decrease in the annual streamflow from 2000 to 2013. Although most of the researches ended in 2013, from the observation of this study the water region continued to

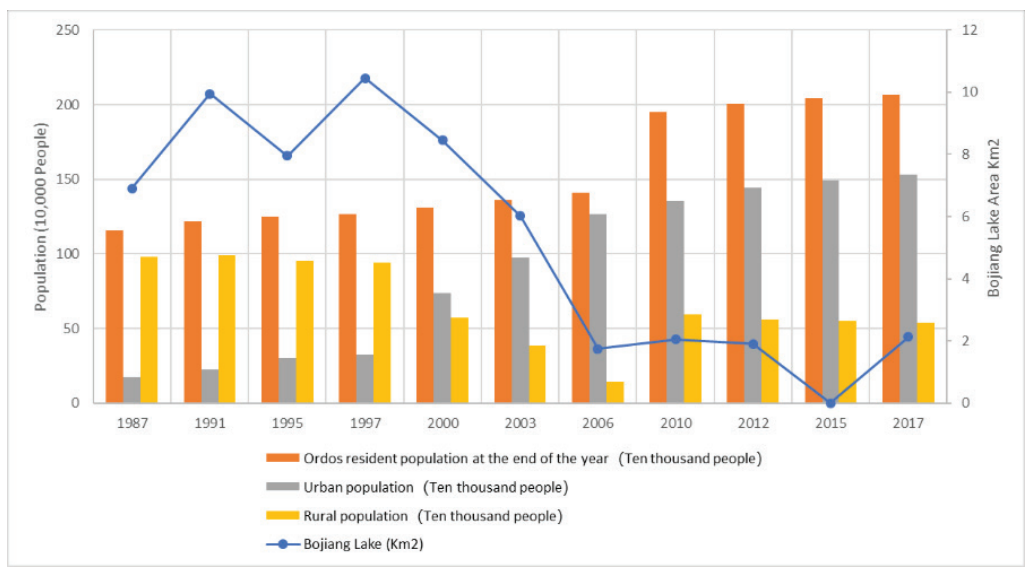

Fig. 8: Ordos city population (overall, rural and urban) Versus Bojiang Lake area. 
experience a reduction in area. From this study, a reduction in precipitation coupled with an increase in evaporation rate was a contributing factor to the reduction in water size. For example, in August where the Landsat images used for this analysis was acquired, the weather conditions during that period were dry and hot exhibiting monthly average temperatures above their mean temperature values except for 1987 and 1995, the annual temperature of the study site, however, showed values above its mean annual temperature values all through the study period. The monthly average precipitation in August was all below the mean precipitation value except for 1995 signifying that August was one of the driest periods of the study (Fig. 9).

\section{CONCLUSION}

The land-use changes experienced in the Ordos Basin between 1987 and 2017 were attributed to the growth in population and economic development in the region. Based on the assessment of the remote sensing images obtained in 1987, 1995, 2003, 2010 and 2017 the five classified regions (grassland, highly vegetated, sparsely vegetated, barren soil and water region) all regions experienced a significant amount of changes which subsequently led to the changes in landscape patterns.
The land use classification and the transition intensity model were used to analyse the changes in the regions over the past 30 years. The changes experienced in the grassland and sparsely vegetated region were observed to be the greatest in the region and these changes were a clear indication of the increased anthropogenic activities such as agricultural activities in the study region.

The future land-use changes were simulated and predicted using the CA-Markov model, and the landcover map changes from 1987 to 2017 . And through this method, the next 30-100 years were predicted and the result shows that grassland and the sparsely vegetated region continued to dominate the study region.

The landscape structural pattern was simulated based on four spatial metrics (patch, shape, diversity and edge metrics) to analyse the fragmentation and heterogeneity level of Ordos basin. The result, however, showed that during the study period the increased population, extensive human activities and urbanization level contributed greatly to the increase in fragmentation and heterogeneity experienced in the region. This effect was reflected in the relationship between the land-use change and the fragmentation level where changes in land use regions except the water region proved to significantly impact the changes in the fragmen-
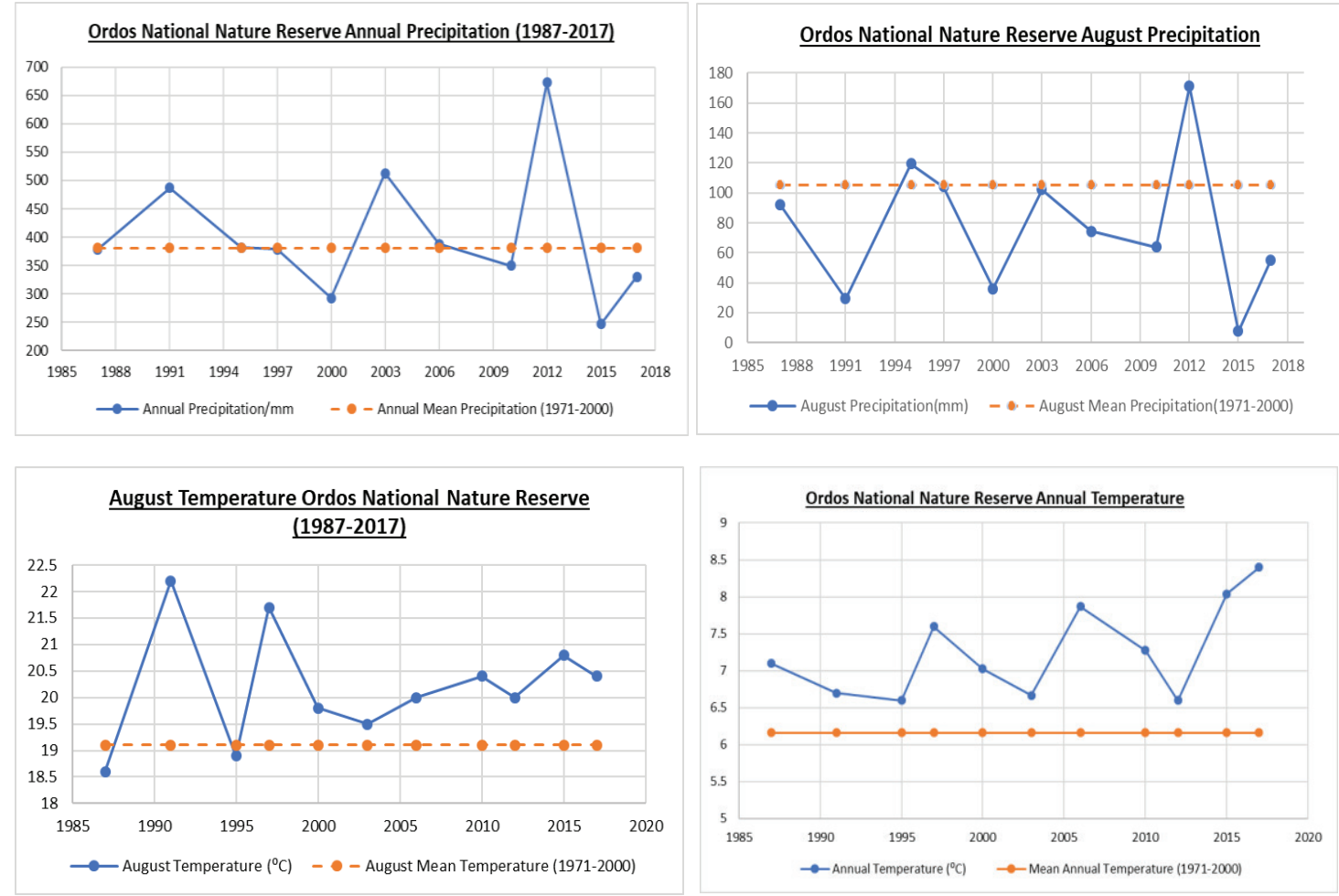

Fig. 9: Weather condition of Ordos national nature reserve. 
tation and heterogeneity level of Ordos basin. Between the 3 -decade study period and the predicted 100 years, it was observed that while the change in fragmentation level showed no relationship with the change in water level, the changes in each land-use regions were both, directly and indirectly, related to the changes in the water region.

Based on our observation in this study, the change in each land use region although showed a significant relationship with the change in water region including Bojiang lake, other external factors also contributed to the changes in the size of the lake an example is the current climatic conditions, increase in urbanization, extensive human activities such as agricultural and industrial activities all of which were accompanied by an increment in the water consumption which posses a long-term impact on the water level as we can see in the predicted images from 2017-2117. Other contributing factors were poor environmental policy and planning involving the building of trap dams which also blocked the flow of water to the lake, changes in the weather conditions such as increased temperature and decreased precipitation all play a role in the reduction in water level. For effective management of the ecosystem, policymakers should keep in mind that changes in land use also affect the regional climate (Foley et al. 2005). With the increased urbanization and extensive human activities in the study region reflected in the land-use changes, it is suggested that policymakers should emphasize more on the continuous management of the land-use changes and improvement of the ecosystem.

\section{ACKNOWLEDGEMENT}

Landsat (http://www.usgs.gov/pubprod/aerial.html\#satellite) programme for providing the remote sensing images used for this research. Also, the authors appreciate the support from the Brook Byers Institute for Sustainable Systems, Hightower Chair and the Georgia Research Alliance at Georgia Institute of Technology.

\section{REFERENCES}

Abdullah, S.A. and Nakagoshi, N. 2006. Changes in landscape spatial pattern in the highly developing state of Selangor, Peninsular Malaysia. Landsc. Urban Plan., 77 (3): 263-275.

Aguilera, F., Valenzuela, L.M. and Botequilha-Leitão, A. 2011. Landscape metrics in the analysis of urban land use patterns: a case study in a Spanish metropolitan area. Landsc. Urban Plan., 99(3): 226-238.

Al-doski, J., Mansor, S.B. and Shafri, H.Z.M. 2013. Change detection process and techniques. Civ. Environ. Res., 3: 37-45.

Aldwaik, S.Z. and Pontius, R.G. Jr. 2012. Intensity analysis to unify measurements of size and stationarity of land changes by interval, category and transition. Landsc. Urban Plan., 106: 103-114.

Aldwaik, S.Z. and Pontius, R.G. Jr. 2013. Map errors that could account for deviations from a uniform intensity of land change. Int. J. Geogr. Inf. Sci., 27: 1717-1739.
Alo, C.A. and Pontius, R.G. Jr. 2008. Identifying systematic land-cover transitions using remote sensing and GIS: The fate of forests inside and outside protected areas of Southwestern Ghana. Environ. Plan. B Plan. Des., 35: 280-295.

Bolund, P. and Hunhammar, S. 1999. Ecosystem services in urban areas. Ecol. Econ., 29: 293-301.

Braimoh, A.K. 2006. Random and systematic land-cover transitions in northern Ghana. Agric. Ecosyst. Environ., 113: 254-256.

Bürgi, M., Hersperger, A.M. and Schneeberger, N. 2004. Driving forces of landscape change-current and new directions. Landsc. Ecol., 19: 857-868.

Cabral, A.I. and Costa, F.L. 2017. Land cover changes and landscape pattern dynamics in Senegal and Guinea Bissau borderland. Appl. Geogr., 82: 115-128.

Cao, C. 2013. Diagnosis of Environmental Health By Remote Sensing. Beijing: Science Press. Chinese.

Cao, C., Zhao, J., Gong, P., Ma, G., Bao, D., Tian, K., Tian, R., Niu, Z., Zhang, H. and $\mathrm{Xu}, \mathrm{M} .2012$. Wetland changes and droughts in southwestern China. Geomat. Nat. Haz. Risk, 3: 79-95.

Chen, Z., Xu, B. and Devereux, B. 2014. Urban landscape pattern analysis based on 3D landscape models. Appl. Geogr., 55: 82-91.

Cyranoski, D. 2009. Putting China's wetlands on the map. Nature, 458: 134.

Dadashpoor, H., Azizi, P. and Moghadasi, M. 2018. Land use change, urbanization, and change in landscape pattern in a metropolitan area. Science of The Total Environment.

Eastman, J.R. 2003. IDRISI Kilimanjaro: Guide to GIS and Image Processing. Worcester (MA): Clark Labs, Clark University.

Echeverría, C., Newton, A., Nahuelhual, L., Coomes, D. and Rey-Benayas, J.M. 2012. How landscapes change: Integration of spatial patterns and human processes in temperate landscapes of southern Chile. Appl. Geogr., 32 (2): 822-831.

Enaruvbe, G.O. and Pontius, R.G. Jr. 2015. Influence of classification errors on intensity analysis of land changes in Southern Nigeria. Int. J. Remote Sens., 36: 244-261.

Finlayson, M.C. 2012. Forty years of wetland conservation and wise use. Aquat. Conserv., 22: 139-143.

Foley, J.A., DeFries, R., Asner, G.P., Barford, C., Bonan, G., Carpenter, S.R., Chapin, F.S., Coe, M.T., Daily, G.C., Gibbs, H.K. and Helkowski, J.H. 2005. Global consequences of land use. Science, 309 (5734): 570-574.

Frondoni, R., Mollo, B. and Capotorti, G. 2011. A landscape analysis of land cover change in the municipality of Rome (Italy): Spatio-temporal characteristics and ecological implications of land cover transitions from 1954 to 2001. Landsc. Urban Plan., 100: 117-128.

Guo, H., Wu, D. and Zhu, H. 1990. Land restoration in China. Acta Ecol. Sin., 10: 24-26. Chinese.

Halabisky, M., Moskal, L.M. and Hall, S.A. 2011. Object-based classification of semi-arid wetlands. J. Appl. Remote Sens., 5: 053511-053513.

He, F., Zhang, Y., Wu, Y. and Gao, T. 1992. The distribution of the relict gull Larus relictus in Maowusu desert, Inner Mongolia, China. Forktail, 7: 151-154.

Hereher, M.E. 2010. Vulnerability of the Nile Delta to sea level rise: an assessment using remote sensing. Geomat. Nat. Haz. Risk., 1: 315-321.

Hladnik, D. 2005. Spatial structure of disturbed landscapes in Slovenia. Ecol. Eng., 24(1-2): 17-27.

Kang, Liang 2017. Quantifying streamflow variations in ungauged lake basins by integrating remote sensing and water balance modelling: a case study of the Erdos Larus relictus National Nature Reserve, China. Remote Sens., 9: 588.

Kertész, Á., Nagy, L.A. and Balázs, B. 2019. Effect of land use change on ecosystem services in Lake Balaton Catchment. Land Use Policy, 80: 430-438.

Kienast, F., Frick, J., Strien, M.J.V. and Hunziker, M. 2015. The Swiss landscape monitoring program - A comprehensive indicator set to measure landscape change. Ecol. Model., 295: 136-150. 
Lausch, A., Blaschke, T., Haase, D., Herzog, F., Syrbe, R.U., Tischendorf, L. and Walz, U. 2015. Understanding and quantifying landscape structure - A review of relevant process characteristics, data models, and landscape metrics. Ecol. Model., 295: 31-41.

Lawler, J.J., Lewis, D.J., Nelson, E., Plantinga, A.J., Polasky, S., Withey, J.C., Helmers, D.P., Martinuzzi, S., Pennington, D. and Radeloff, V.C. 2014. Projected land-use change impacts on ecosystem services in the United States. Proc. Natl. Acad. Sci., 111(20): 7492-7497.

Lehner, B. and Doll, P. 2004. Development and validation of a global database of lakes, reservoirs and wetlands. J. Hydrol., 296: 1-22.

Liang, K., Lou, H. and Cheng, C. 2011. Characteristics of groundwater flow in the Ordos Larus relictus reserve wetland. Resour. Sci., 33(6): 1089-1098 (in Chinese).

Liu, W., Zhang, L., Xing, X., Bao, X., Su, Y., Bai, Z., Ren, Y. and Gao, R. 2008. The relationship between the zoobenthos and Larus relictus' foraging behavior in saline-alkaline wetland of Ordos Plateau. J. Arid Land Resour. Environ., 22: 185-192. Chinese.

Lu, D. and Weng, Q. 2007. A survey of image classification methods and techniques for improving classification performance. International Journal of Remote Sensing, 28: 823-870.

Luck, M. and Wu, J. 2002. A gradient analysis of urban landscape pattern: a case study from the Phoenix metropolitan region, Arizona, USA. Landsc. Ecol., 17(4): 327-339.

Mallinis, G., Koutsias, N. and Arianoutsou, M. 2014. Monitoring land use/land cover transformations from 1945 to 2007 in two peri-urban mountainous areas of Athens metropolitan area, Greece. Sci. Total Environ., 490: 262-278.

McGarigal, K., Cushman, S.A. and Stafford, S. 2000. Multivariate Statistics for Wildlife and Ecology Research. Springer Science \& Business Media.

Mwangi, H., Lariu, P., Julich, S., Patil, S., McDonald, M. and Feger, K.H. 2017. Characterizing the intensity and dynamics of land-use change in the Mara River Basin, East Africa. Forests, 9(1): 8.

Nagendra, H., Munroe, D.K. and Southworth, J. 2004. From pattern to process: landscape fragmentation and the analysis of land use/land cover change. Agric. Ecosyst. Environ., 101(2): 111-115.

Phiri, D. and Morgenroth, J. 2017. Developments in landsat land cover classification methods: a review. Remote Sens., 9: 967.

Pontius, R.G. Jr., Gao, Y., Giner, N.M., Kohyama, T., Osaki, M. and Hirose, K. 2013. Design and interpretations of intensity analysis illustrated by land change in Central Kalimantan, Indonesia. Land., 2: 351-369.

Pontius, R.G. Jr., Shusas, E. and McEachern, M. 2004. Detecting important categorical land changes while accounting for persistence. Agric. Ecosyst. Environ., 101: 251-268.

Ramsar 2007. What are wetlands? In: The RAMSAR convention of wetlands information paper no. 1. Available from: http://www.ramsar.org.

Reis, J.P., Silva, E.A. and Pinho, P. 2015. Spatial metrics to study urban patterns in growing and shrinking cities. Urban Geogr., 3638: 1-26.
Ren, H., Shen, W.J., Lu, H.F., Wen, X.Y. and Jian, S.G. 2007. Degraded ecosystems in China: status, causes, and restoration efforts. Landscape and Ecological Engineering, 3: 1-13.

Rosenfield, G.H. and Fitzpatrick-Lins, K. 1986. A coefficient of agreement as a measure of thematic classification accuracy. Photogramm. Eng. Remote Sensing, 52: 223-227.

Sang, L., Zhang, C., Yang, J., Zhu, D. and Yun, W. 2011. Simulation of land use spatial pattern of towns and villages based on CA-Markov model. Math. Comput. Model., 54: 938-943.

Schröder, B. and Seppelt, R. 2006. Analysis of pattern-process interactions based on landscape models-overview, general concepts, and methodological issues. Ecol. Model., 199: 505-516.

Szabó, S., Bertalan, L., Kerekes, Á. and Novák, T.J. 2016. Possibilities of land use change analysis in a mountainous rural area: a methodological approach. Int. J. Geog. Inf. Sci., 30(4): 708-726.

Teixeria, Z., Teixeria, H. and Marques, J.C. 2014. Systematic processes of land use/land cover change to identify driving forces: implications on water quality. Sci. Total Environ., 470-471: 1320-1335.

Tian, R., Cao, C., Peng, L., Ma, G., Bao, D., Guo, J. and Yomwan, P. 2016. The use of HJ-1A/B satellite data to detect changes in the size of wetlands in response into a sudden turn from drought to flood in the middle and lower reaches of the Yangtze River system in China. Geomatics, Natural Hazards and Risk., 7: 287-307.

Tyre, A.J., Tenhumberg, B. and Michael Bull, C. 2006. Identifying landscape-scale patterns from individual scale processes. Ecol. Model., 199: 442-450.

Wan, L., Zhang, Y., Zhang, X., Qi, S. and Na, X. 2015. Comparison of land use/land cover change and landscape patterns in Honghe National Nature Reserve and the surrounding Jiansanjiang. Ecol. Indic., 51: 205-214.

Young, N.E., Anderson, R.S., Chignell, S.M., Vorster, A.G., Lawrence, R. and Evangelista, P.H.A. 2017. Survival guide to Landsat preprocessing. Ecology, 98: 920-932.

Yu, X. and Ng, C. 2006. An integrated evaluation of landscape change using remote sensing and landscape metrics: a case study of Panyu, Guangzhou. Int. J. Remote Sens., 27(6): 1075-1092.

Yuan, Y., Li, B., Gao, X., Liu, H., Xu, L. and Zhou, C.A. 2016. method of characterizing land-cover swap changes in the arid zone of China. Front. Earth Sci., 10: 74-86.

YuhaiBao, SuyaBao and Yinshan 2011. Analysis on temporal and spatial changes of landscape pattern in Dalinor Lake Wetland. Procedia Environ. Sci., 10: 2367-2375.

Zaehringer, J.G., Eckert, S. and Messerli, P. 2015. Revealing regional deforestation dynamics in North-Eastern Madagascar-Insights from multi-temporal land cover change analysis. Land., 4: 454-474.

Zedler, J.B. and Kercher, S. 2005. Wetland resources: status, trends, ecosystem services, and restorability. Annu. Rev. Environ. Resour., 30: 39-74. 